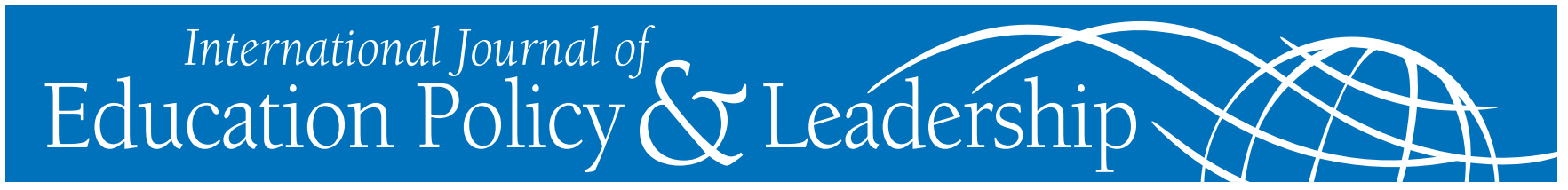

\title{
Outdoor Play and Learning: Policy and Practice ${ }^{1}$
}

\author{
KATHLEEN BURRISS \\ Middle Tennessee State University \\ LARRY BURRISS \\ Middle Tennessee State University
}

\begin{abstract}
This study describes national school district policy and practice regarding elementary school children's outdoor learning and play. District representatives from 173 randomly selected school districts completed questionnaires describing policy and practice related to recess, outdoor play, outdoor curricular studies, playground materials, ADA accessibility, and administrative support. Quantitative analyses indicate that although the largest proportion of school districts overall reported maintaining the same amount of outdoor activity time, more school districts reported decreasing time spent outdoors than school districts that reported increasing children's time outside. There were no significant differences in variables across the three different-sized school districts. These data are congruent with other findings indicating that decreasing children's outdoor time is a national trend. Data suggest administrators' greater support for outdoor play and learning than previously identified. These findings are discussed as an opening dialogue between administration and teachers to plan for children's quality outdoor experiences.
\end{abstract}

Burriss, K. G., \& Burriss, L. (2011). Outdoor play and learning: Policy and practice. International Journal of Education Policy and Leadership, $6(8)$.

\section{Background: Why Go Outdoors?}

In an effort to help children meet life's challenges, educators are responsible for preparing quality learning arenas. The purpose of this article is to explore the potential of the school outdoor environment and, in doing so, describe the relationship among educators' perceptions, education policy, and outdoor practice.

There is a wide variety of ways in which children learn and play outside. Sommerset (2000) defines outdoor schooling as learning both about and in the community. The outdoors becomes a natural extension of the indoor classroom. Children's outdoor experiences build on and serve to extend traditional indoor learning. Lieberman and Hoody (1998) believe using the Environment as an Integrating Context (EIC) serves as "a framework for interdisciplinary, collaborative, student-centered, hands-on, and engaged learning" (p. 1).

The advantages of EIC programs include "better performance on standardized measures of academic achievement in reading, writing, math, science, and social studies; reduced discipline and classroom management problems; increased engagement and enthusiasm for learning; and, greater grade and ownership in accomplishments" (p. 1). Findings indicate when children engage in outdoor activities, there is a stronger knowledge base and empathic regard toward environmental issues. When engaged in outdoor activities, students are more likely to protect the environment (Kenney, Militana, \& Donohue, 2003). The literature clearly demonstrates the importance of outdoor play for children's cognitive, socialemotional, and physical development (Burriss \&

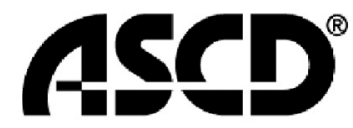

LEARN. TEACH. LEAD.

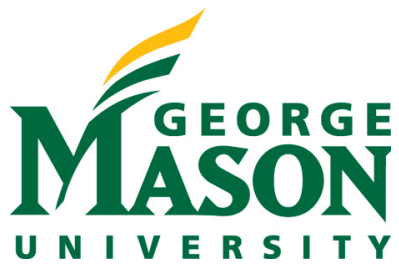


Foulks-Boyd, 2005), as well as illustrate the consequences of play deprivation for infants and young children (Frost, Wortham, \& Reifel, 2005). Frost (2005) describes deliberate play deprivation analogous to child abuse; the child is impaired in growth, development or psychological functioning. He argues for "good play," play that promotes the triad of social, physical and cognitive skills. (p. 12).

\section{Cognitive Development}

Cognitive development occurs not only during structured outdoor activities, but during recess as well. The highly structured school-day schedule is intense. This is particularly true for younger children who are not yet cognitively mature enough to perform highly structured complex tasks effectively. Some educators decrease or eliminate recess because they believe that providing children with extended instructional time ensures additional learning; however, the contrary occurs. Children, like adults, require recovery time from highly structured routines (Pellegrini $\&$ Bohn, 2005). For some, this recovery might be rigorous group activity. Others might choose playing with one or two peers; for still others, recovery might be a solitary effort. Recess provides a choice of activity and level of peer interaction.

The time spent in quality recess allows children to recover from the school schedule in an unstructured way that allows them to continue traditional indoor classroom lessons with renewed attention. Instead of more time on task, distributing children's efforts between structured and unstructured tasks proves beneficial. This asset is explained as a consequence of understanding the relationship between Piaget's (1983) developmental stage theory (Pellegrini $\&$ Bohn, 2005) and the concept of distributed effort (Pellegrini \& Bjorkland, 1996).

Children's, especially young children's, immature nervous system and limited experience undermine their ability to perform higher-level cognitive tasks with the same proficiency as older children and adults (Pellegrini \& Bjorkland, 1996). This immaturity is not a deficit to be overcome with additional time on task or achieved with the addition of further information; rather, it is a consequence of both growth and experience. Interference builds when children who are not yet cognitively mature, repeat highly structured tasks. The unstructured nature of recess, especially for younger children, helps to decrease learning interference. This benefit is not shared by merely allowing children to move from one focused activity to another structured task, nor does structured physical education (PE) activity provide for children's recovery time. Unstructured activity and free choice decreases the interference for learning (Pellegrini \& Bohn, 2005). In other words, it is not merely a question of allowing time outdoors in play; unstructured play provides children a renewed engagement with learning to occur.

During recess, children engage in real-life situations and confront relevant problems. Situations may involve playing an organized game with peers, gaining access to playground equipment, or initiating a relationship for companionship. In each instance, in order to be successful, children learn to focus on and assume the perspective of others. They negotiate, communicate, and compromise. Appropriate verbal and nonverbal communication is essential. In order to be effective players, children accurately interpret the signals and cues offered by others (Katz \& McClellan, 1997).

Play provides children with opportunities for concept development; they test out and refine existing world concepts (Stone, 2005). "In mud play, the children develop concepts of mass, volume, and the nature of change" (p. 42). Recess time is not merely physical activity. Rather, it provides children with stimulating intellectual activity.

\section{Social Development}

Recess and outdoor play activities contribute to children's social learning and development. Rubin (1980) believes play is the primary way for children to develop socially. Children rehearse a variety of strategies to enter and maintain play. In order to be effective players, they cooperate, share, and reconcile differences. The unstructured nature of recess and outdoor play maximizes children's opportunities to approximate, test, and review their social approach and maintenance efforts.

Perspective-taking, while intellectual, is also highly significant for children's social development. Perspective-taking refers to a child's ability to simultaneously differentiate their own perspective from 
another and further recognize that the other's perspective may be different from their own (Kostelnik, Soderman, Stein, \& Whiren, 1993). Children's ability to perspective-take ensures effective interactions with others. Adult modeling and adult think-alouds ("How would you feel if...?") assist children, but children's practice and approximations contribute to building a repertoire of social strategies as well. "What do I do or say in this particular situation to gain access?" "What did I do or say to please or displease this group?" Finally, "How can I tell if this group thinks and feels differently than I do?" Children begin to realize that their actions influence others' thoughts, feelings, and behavior.

Teachers ensure positive social interactions by facilitating children's understanding that caring, kind, and prosocial behaviors have a greater benefit to themselves as much as they help others. When children assist others through a range of prosocial behaviors, they develop feelings of satisfaction and social competence (Katz \& McClellan, 1997; Kostelnik et al., 1993). Social competence is complex and refers to relationship building and maintenance with others (Katz \& McClellan, 1997).

Some argue that the unstructured outdoor arena appears to highlight both bullying and victim behaviors (Left, Power, Costigan, \& Manz, 2003). There are several components that nurture children's quality social interactions and diminish bullying and victimization. The general nature of the school climate (quality of trust and respect), school order and discipline, student interpersonal relationships, and student-teacher relationships are significant toward this end (Leff et al., 2003). It is important to provide ageand gender-appropriate structured choices on the playground. Active adult monitoring during recess decreases aggression and increases prosocial interactions among children. Finally, structured activities in sections of the playground and adult supervision contribute to children's cooperative play and decreased aggression (Leff et al., 2003). Schoolwide intervention programs show a reduction in numbers of victims of bullying (Hall, 2006). The point is the outdoor area serves as a natural environment to nurture prosocial behavior and diminish bullying; educators help children effectively interact with one another.

\section{Emotional Development}

For many children, recess and other outdoor activities may be the single source of positive reinforcement in the school day. Not confined to traditional classroom tasks, children freely demonstrate noncurricular strengths. As children explore the outdoor environment, they test their abilities. During recess and in the outdoors, children acclaim one another for their running, jumping, swinging, and climbing abilities. The child who has difficulty with reading, writing, or numeracy may be knowledgeable about plants, animals, or weather. Children become both leaders and followers; they practice perseverance, self-discipline, responsibility, and self acceptance. A unique learning derives from children playing with one another (NAECS, 2001). In order to play well, children learn to take others' perspectives, send and interpret social cues, and use language effectively.

Children's ability to form and maintain relationships with age-mates is important for success later in life. Unlike the admittedly important adult-child relationship, age-mates understand relevance in the world of children. They support one another, provide guidance, and become important to each otherchildren begin to feel valued. When children consistently have difficulty initiating and maintaining friendships, findings suggest they are more likely to become juvenile delinquents, drop out of school, receive dishonorable discharges from the armed services, experience psychiatric problems, or commit suicide. Children's abilities to engage in quality relationships are critical toward their life's satisfaction in later years (Kostelnik, et al., 1993).

\section{Physical Development}

Outdoor activity and recess provide children with physical movement and exercise. In conjunction with good nutrition, physical activity is critical to weight maintenance, contributes to children's psychological well-being, and assists in bone development (Author $\&$ Harrison, 2004). Physical activities such as running, jumping, kicking or swinging provide the brain with a renewed supply of blood. In addition, physical activity causes natural chemicals to support greater numbers of connections between neurons (Healy, 1998). Children with sedentary parents tend to also be inactive (Sothern \& Gordon, 2003). 
Parents' work schedules, lack of appropriate playscapes, and fear of strangers result in many children no longer engaging in outdoor neighborhood play. Children's after-school activities (i.e., sports, music, dance) often take the time previously used for spontaneous outdoor play. Structured after-school activities differ from outdoor unstructured play and do not replace the cognitive, social-emotional, and physical benefits of outdoor play. In this hurried society, the need to protect recess and outdoor play time becomes further evident. Recess and outdoor learning may be the only time children have to explore the outdoors with peers. Findings indicate that when physical activity is restricted, children do not attempt to compensate for this inactivity after school. In contrast, children showed greater after-school physical activity after engaging in physical activity during the school day (Dale, Corbin, \& Dale, 2002).

After engaging in recess, children display greater focus on tasks and less fidgeting (Jarrett et al., 1998). Although the cognitive, social-emotional, and physical attributes of recess correlate with school success (Pellegrini \& Bohn, 2005), Alexander (1999) reports that approximately 40 percent of American schools decreased or eliminated recess breaks. Kieff (2001) believes that many teachers, parents, and policymakers underestimate the benefits of recess to quality instruction.

Some reasons given for decreasing school recess include fear of playground injury lawsuits, issues regarding questionable or suspicious adults in the play vicinity, shortage of qualified adult supervisors, additional time needed for instruction (Chmelynski, 1998), time on task, and accountability related to the No Child Left Behind act (Pellegrini \& Bohn, 2005). Recess, however, provides children with a variety of learning opportunities not possible in the traditional indoor classroom.

\section{What About Recess?}

Recess is defined as blocks of unstructured time, typically outdoors, when children freely choose activities and playmates. Recess allows for creativity, freedom, and independence (Chmelynski, 1998). Kieff (2001) describes high-quality recess experiences as those where children of all ages engage a variety of choices in their activities. The literature clearly identifies how recess benefits children's cognitive, physical, and social-emotional development (Pellegrini \& Bjorkland, 1996; Pellegrini \& Bohn, 2005; Pellegrini, Huberty, \& Jones, 1995; Pellegrini \& Smith, 1993).

Unstructured recess and play differ from the structured learning activities taking place in the outdoor classroom with respect to motivation, choice, and vigorous activity. Both structured and unstructured outdoor activities are important for children's development; appropriately designed, the outdoor arena accommodates multiple forms of play and physical activity.

\section{The Outdoor Classroom}

In addition to the developmental benefits children achieve during the unstructured and free choice of recess, the outdoors offers further opportunities to integrate traditional curricular standards. This means that beyond the playground and sports areas, educators use the school grounds as potential learning spaces for children. Urban, suburban, and rural school settings maximize the available landscape, resources, and space for of a range of developmental levels. Although available space and budgets define parameters for planning outdoor learning experiences, some basic tenets ensure all children, regardless of school setting, enjoy outdoor learning opportunities.

The National Clearinghouse for Educational Facilities (NCEF) highlights the quality of openendedness as critical in designing space for children's outdoor learning (Wagner, 2000). First, consider who will be using the space and what types of play will occur. For example, preschoolers with their rapid behavioral development will differ from elementary children's interests in both equipment and space. The NCEF suggests creating nonspecific-use spaces with adjustable seating as important. Instead of a vast field, a pond, or a baseball diamond, outdoor classrooms include adjacent covered porches, amphitheaters, or picnic tables. In addition to implementing a variety of curricula, flexible seating ensures children's socialization. Portable tables and chairs facilitate using the outdoors as a classroom. The outdoor classroom may begin with a picnic table, a few benches, or a window sill or pole bird 
feeder. The NCEF asserts, however, that trees and plants do not necessarily define elements in the outdoor classroom (2000). Rather , details that facilitate use of the school grounds include "outdoor storage areas, access to running water, lighting, overhead shelter, seating, signage, and trash receptacles" (p. 6). Just as it is important to define learning centers in the indoor classroom, the outdoor classroom clearly distinguishes play areas in order to promote quality interactions. Depending on the landscape, these divisions may be natural or man-made. Rural or suburban play areas provide space and include a variety of plant life. Numerous textures, such as dirt, sand, water, and rocks, provide children with greater learning opportunities. Urban schools, however, may stack outdoor areas onto cafeteria and parking garage roofs and use man-made walls to separate play areas (NCEF, 2000). The key is flexibility in planning. Educators maximize quality playscapes relative to the setting.

\section{The Problem}

In order to support children's quality outdoor play and learning experiences, the congruency between policy and practice needs to be examined. This is particularly important in light of three national trends. First, childhood obesity has been on the rise for decades in all racial, ethnic, age, and gender groups. In some subgroups, more than 30 percent of children are overweight (Sothern \& Gordon, 2003). The obesity rates have tripled since 1970 for schoolage children and adolescents (ADA, 2003b). There is no single reason for children becoming overweight. Low physical activity is identified as a cause, along with poor nutrition, unhealthy eating, and eating for the wrong reasons (Archer, 1989; Sothern \& Gordon, 2003). In addition to maintaining a healthy weight, physical activity contributes to children's psychological well-being and assists bone development. Findings indicate that 48 percent of girls and 26 percent of boys do not exercise vigorously on a regular basis. Parents can no longer rely on physical education (PE) classes or recess for their children's exercise. Participation in school PE classes is declining (ADA, 1999). Further, PE classes do not provide children with the recommended amount of vigorous physical activity (National Institute of Child Health and Human Development Study of Early Child Care and Youth Development Network, 2003). Children indicate that they do not know what it means to be physically fit. They relate fitness with performance, excelling in sports, having big muscles, and being more popular (Sullivan, 2003).

Complicating the issue of children's lack of vigorous exercise is the increased demand for supervised after-school care. The increased numbers of working parents and single-parent households undermine children's opportunities for free and unstructured neighborhood play. Schools that have limited physical playscapes and have fewer after-school personnel frequently limit after-school events to indoor and sedentary activities.

In many cases, children are restricted from outdoor activities both during and after school. With the current focus on children scoring well on standardized tests, some administrators have decreased or eliminated outdoor recess altogether. Consequently, scheduling outdoor play and recess is difficult. Data indicate that from 1981 to 1997 , children spent more than eight additional hours per week in school than they did in the early 1980s and one hour more in study at home. This figure compares with a decrease in time spent in outdoor playtime (Hofferth $\&$ Sandberg, 2000). Despite the multiple benefits for children's learning and development, outdoor play and recess time appears to be on the decline in public schools.

\section{Method}

\section{Participant Selections}

The National Center for Educational Statistics (NCES: http://nces.ed.gov/) provides a wealth of available data for research projects. For this particular study, researchers used an NCES database of all school districts in the United States ranked by student population. This list was stratified into three groups: district student populations above 45,000, student populations between 20,000 and 45,000, and populations below 20,000. This list was divided into three approximately equal groups based on population, not on the number of schools in each group. These districts were labeled as "small," "medium" and "large."

At the second stage, a random list of the three designated-by-size districts was generated using the 
SPSS statistical package. Using this randomly selected population, questionnaires were mailed to approximately 500 districts, of which 173 responded ( $n=69$ small, $n=57$ medium, and $n=47$ large).

\section{Instrument}

The survey used a 1-5 Likert scale for 8 items (see Table 1).

\begin{tabular}{|l|l|l|l|l|l|}
\hline Table 1: Survey Questions & $\begin{array}{l}\text { Strongly } \\
\text { Disagree }\end{array}$ & Disagree & $\begin{array}{l}\text { No } \\
\text { Opinion }\end{array}$ & Agree & $\begin{array}{l}\text { Strongly } \\
\text { Agree }\end{array}$ \\
\hline Outdoor time is provided for children with disabilities & & & & & \\
\hline $\begin{array}{l}\text { Playground and playground equipment are in adequate } \\
\text { condition }\end{array}$ & & & & & \\
\hline $\begin{array}{l}\text { Playground equipment is varied (swing, slides, climbing, } \\
\text { etc.) }\end{array}$ & & & & & \\
\hline $\begin{array}{l}\text { Playground has moveable equipment (bicycles, scooters, } \\
\text { blocks, etc.) }\end{array}$ & & & & & \\
\hline $\begin{array}{l}\text { Playground equipment includes balls, jump ropes, etc. } \\
\text { Playground area includes space for activities (running and } \\
\text { ball games) }\end{array}$ & & & & & \\
\hline $\begin{array}{l}\text { Playground area has varied texture (pavement, grass, } \\
\text { sand, etc.) }\end{array}$ & & & & & \\
\hline $\begin{array}{l}\text { Playground area has places for reflection such as shade } \\
\text { trees, gazebos, benches, etc. }\end{array}$ & & & & & \\
\hline
\end{tabular}

\section{Analysis and Results}

\section{Analysis}

For this project, four sets of analyses were run using the SPSS statistical package.

As noted earlier, the authors were particularly interested in district level administrators' perceptions toward their district-wide playgrounds and possible connections between their understandings and outdoor learning and play. Table 2 shows that only 40 percent of the district administrators said they have a written policy regarding outdoor learning.

Table 2: Does Your School Have A Written Policy About Outdoor Learning And Play

\begin{tabular}{lll} 
& Frequency & Percent \\
Yes & 64 & 40.0 \\
No & 96 & 60.0 \\
Total & 160 & 100.0 \\
\hline
\end{tabular}

Table 3 shows responses to the question, "How has the time for outdoor play changed in recent years?" More than 32 percent of the administrators said the time for outdoor play has decreased, 62 percent said the time for outdoor play has stayed the same, and less than 6 percent said time for outdoor activities has increased.

Table 3: How Has Time Allowed For Outdoor Play Changed In Recent Years

\begin{tabular}{lll}
\hline & Frequency & Percent \\
Greatly decreased & 10 & 5.8 \\
Decreased & 45 & 26.5 \\
Remained the same & 106 & 62.4 \\
Increased & 9 & 5.3 \\
Total & 170 & 100.0 \\
\hline
\end{tabular}

As can be seen in Table 4 (next page), there were significant differences in how administrators answered the eight relevant questions. All results were significant at less than 0.001 , indicating a wide range 
of activities, equipment, and philosophies about outdoor play.

Remember, these data show district administrators' perceptions about playgrounds and activities, not what the playgrounds are actually like. There were, nevertheless, commonalities among these perceptions. In this regard a principal axis factor analysis with Varimax rotation was run to determine any un- derlying relationships among the eight variable questions. Three factors were requested. After rotation, the first factor accounted for 17.1 percent of the variance, the second factor accounted for 17.0 percent, and the third factor accounted for 8.5 percent. Table 5 displays the items and their factor loadings for the rotated factors (for clarity, loadings less than 0.30 are omitted).

\begin{tabular}{|c|c|c|c|c|c|c|c|}
\hline & $\begin{array}{l}\text { Strongly } \\
\text { Disagree }\end{array}$ & Disagree & $\begin{array}{c}\text { No } \\
\text { Opinion }\end{array}$ & Agree & $\begin{array}{l}\text { Strongly } \\
\text { Agree }\end{array}$ & Total & Sig. \\
\hline $\begin{array}{l}\text { Outdoor time is provided for } \\
\text { children with disabilities }\end{array}$ & $\begin{array}{c}2 \\
(1.4)\end{array}$ & $\begin{array}{c}0 \\
(0.0)\end{array}$ & $\begin{array}{c}2 \\
(1.4)\end{array}$ & $\begin{array}{c}41 \\
(27.7)\end{array}$ & $\begin{array}{c}103 \\
(69.6)\end{array}$ & $\begin{array}{c}148 \\
(100)\end{array}$ & $<0.001$ \\
\hline $\begin{array}{l}\text { Playground and playground } \\
\text { equipment are in adequate con- } \\
\text { dition }\end{array}$ & $\begin{array}{c}2 \\
(1.4)\end{array}$ & $\begin{array}{c}8 \\
(5.4)\end{array}$ & $\begin{array}{c}15 \\
(10.1)\end{array}$ & $\begin{array}{c}57 \\
(38.5)\end{array}$ & $\begin{array}{c}66 \\
(44.6)\end{array}$ & $\begin{array}{l}148 \\
(100)\end{array}$ & $<0.001$ \\
\hline $\begin{array}{l}\text { Playground equipment is varied } \\
\text { (swing, slides, climbing, etc.) }\end{array}$ & $\begin{array}{c}2 \\
(1.4)\end{array}$ & $\begin{array}{c}2 \\
(1.4)\end{array}$ & $\begin{array}{c}14 \\
(9.5)\end{array}$ & $\begin{array}{c}55 \\
(37.2)\end{array}$ & $\begin{array}{c}75 \\
(50.7)\end{array}$ & $\begin{array}{c}148 \\
(100)\end{array}$ & $<0.001$ \\
\hline $\begin{array}{l}\text { Playground has moveable } \\
\text { equipment (bicycles, scooters, } \\
\text { blocks, etc.) }\end{array}$ & $\begin{array}{c}39 \\
(26.9)\end{array}$ & $\begin{array}{c}54 \\
(37.2)\end{array}$ & $\begin{array}{c}23 \\
(15.9)\end{array}$ & $14(9.7)$ & $\begin{array}{c}15 \\
(10.3)\end{array}$ & $\begin{array}{l}145 \\
(100)\end{array}$ & $<0.001$ \\
\hline $\begin{array}{l}\text { Playground equipment includes } \\
\text { balls, jump ropes, etc. }\end{array}$ & $\begin{array}{c}2 \\
(1.4)\end{array}$ & $\begin{array}{c}6 \\
(4.1)\end{array}$ & $\begin{array}{c}9 \\
(6.2)\end{array}$ & $\begin{array}{c}46 \\
(31.7)\end{array}$ & $\begin{array}{c}82 \\
(56.6)\end{array}$ & $\begin{array}{l}145 \\
(100)\end{array}$ & $<0.001$ \\
\hline $\begin{array}{l}\text { Playground area includes space } \\
\text { for activities (running and ball } \\
\text { games) }\end{array}$ & $\begin{array}{c}0 \\
(0.0)\end{array}$ & $\begin{array}{c}0 \\
(0.0)\end{array}$ & $\begin{array}{c}4 \\
(2.7)\end{array}$ & $\begin{array}{c}53 \\
(35.8)\end{array}$ & $\begin{array}{c}91 \\
(61.5)\end{array}$ & $\begin{array}{c}148 \\
(100)\end{array}$ & $<0.001$ \\
\hline $\begin{array}{l}\text { Playground area has varied tex- } \\
\text { ture (pavement, grass, sand, etc.) }\end{array}$ & $\begin{array}{c}2 \\
(1.4)\end{array}$ & $\begin{array}{c}5 \\
(3.4)\end{array}$ & $\begin{array}{c}11 \\
(7.4)\end{array}$ & $\begin{array}{c}53 \\
(35.8)\end{array}$ & $\begin{array}{c}77 \\
(52.0)\end{array}$ & $\begin{array}{c}148 \\
(100)\end{array}$ & $<0.001$ \\
\hline $\begin{array}{l}\text { Playground area has places for } \\
\text { reflection such as shade trees, } \\
\text { gazebos, benches, etc. }\end{array}$ & $\begin{array}{c}10 \\
(6.8)\end{array}$ & $\begin{array}{c}20 \\
(13.6)\end{array}$ & $\begin{array}{c}27 \\
(18.4)\end{array}$ & $\begin{array}{c}55 \\
(37.4)\end{array}$ & $\begin{array}{c}35 \\
(23.8)\end{array}$ & $\begin{array}{c}147 \\
(100)\end{array}$ & $<0.001$ \\
\hline
\end{tabular}

Factor 1, defined here as "The Physical Playground," shows high factor loadings on questions related to playground usage.

Factor 2, "Diversity of Activity," shows high factor loadings that suggest that different textures afford a range of places for a wide variety of activities involving atypical as well as typical children.

Factor 3, "Multiple Usage," indicates a strong relationship between varied textures and portable play equipment such as balls and jump ropes, as well as places for more reflective activities.

As seen in Table 5 (next page), the question about playground texture was present in all three fac- tors. Interestingly, when school size (small, medium, or large) was compared across the eight questions used in the Chi-Square analysis, there were no significant differences except for the question involving textures on playgrounds (pavement, grass, sand, etc.). Thus, Table 6 (page 9) shows a significant difference among the three school sizes with respect to different textured playgrounds. In addition, the Goodman and Kruskal tau, a directional test, shows a significant difference based on school size (texture dependent). 


\section{Discussion}

These findings support other research describing a national trend toward limiting recess time (Alexander, 1999; Jarrett, 2001). Yet, these data also provide a positive interpretation to reverse declining outdoor activity and build toward a new understanding.
Past research findings identified three reasons why school districts justified eliminating outdoor activities: there is no time because more instruction is needed for raising test scores; recess disrupts the children's work patterns, causing them to be more excited and less attentive; and recess encourages aggressive and antisocial behavior (Pellegrini, 1995).

Table 5: Rotated Factor Matrix

\begin{tabular}{|c|c|c|c|}
\hline & & Factor & \\
\hline & 1 & 2 & 3 \\
\hline Playground equipment is varied (swing, slides, climbing, etc.) & 0.835 & & \\
\hline Playground and playground equipment are in adequate condition & 0.647 & & \\
\hline $\begin{array}{l}\text { Playground area has places for reflection such as shade trees, gazebos, benches, } \\
\text { etc }\end{array}$ & 0.402 & & 0.357 \\
\hline Playground area includes space for activities (running and ball games) & & 0.749 & \\
\hline Playground equipment includes balls, jump ropes, etc. & & 0.656 & 0.319 \\
\hline Outdoor time is provided for children with disabilities & & 0.422 & \\
\hline Playground area has varied texture (pavement, grass, sand, etc.) & 0.370 & 0.499 & 0.608 \\
\hline $\begin{array}{l}\text { Extraction Method: Principal Axis Factoring } \\
\text { Rotation Method: Varimax with Kaiser Normalization } \\
\text { Rotation converged in } 6 \text { iterations }\end{array}$ & & & \\
\hline
\end{tabular}

In order to reverse a national trend toward devaluing children's outdoor time, definitive data related to decision-making are helpful. Is decreasing outdoor learning and play opportunities an explicit or implicit district-level directive? Data indicate that only 40 percent of the school districts had a designated policy describing outdoor school activities. A written school policy describing outdoor learning possibilities would be helpful for individual building principals, classroom teachers, and parents. If there is confusion regarding what constitutes meaningful outdoor activity, a written policy would legitimize arranging different alternatives. For example, the outdoor classroom (structured events related with curriculum and state standards) provides instruction associated with, among others, science, geography, and language arts. In the outdoors, such curricular integration opportunities allow students to use materials, applications, and motor coordination activities not possible in the indoor classroom. For example, the natural landscape of the outdoors (rocks, trees, water) become materials for investigation; scavenger hunts and geocaching allow children a range of exploration events; and the larger space of the outdoors ensures greater movement and innovation during performances, games, and exhibitions. A written policy demonstrates a school district's commitment to curricular innovation.

In addition to supervised or structured outdoor physical education activities, a written policy designation could legitimize walking and biking clubs and nature trails (structured or unstructured, supervised). A definition of play typically refers to an unstructured activity. Unstructured means it is motivated by the child and not prescribed by the teacher. This unstructured activity could be vigorous or reflective, group oriented or solitaire, and involve gross or small motor coordination. Rather than insisting on an organized game or activity, children could engage in high-quality unstructured (supervised) play during recess. A written district policy legitimizes a range of outdoor activities and provides guidelines for individual building principals, classroom teachers, and parents. It may also prove beneficial when approaching the community for support. Community businesses are more likely to support an outdoor building project (storage, amphitheater, green house, gazebo), equipment (climbing apparatus, track, wheel 
toys), or maintenance (sandbox, mulch, dirt mounds) projects when the district evidences a policy commitment toward this end.

\begin{tabular}{|c|c|c|c|c|}
\hline \multicolumn{5}{|l|}{$\begin{array}{l}\text { Table 6: } \\
\text { Texture }\end{array}$} \\
\hline \multirow{5}{*}{$\begin{array}{l}\text { School } \\
\text { size }\end{array}$} & \multirow{5}{*}{$\begin{array}{l}\text { Small } \\
\text { Medium } \\
\text { Large }\end{array}$} & \multicolumn{2}{|c|}{$\begin{array}{c}\text { Area has varied } \\
\text { textures }\end{array}$} & \multirow[t]{2}{*}{ Total } \\
\hline & & Disagree & Agree & \\
\hline & & 1 & 54 & 55 \\
\hline & & 1 & 46 & 47 \\
\hline & & 5 & 30 & 35 \\
\hline Total & & 7 & 130 & 137 \\
\hline \multicolumn{5}{|c|}{$\begin{array}{l}\text { Chi }- \text { Square }=8.169, \mathrm{df}=2, \mathrm{p}=0.017 \\
\text { Goodman and Kruskal tau }=0.060 \text { with texture de- } \\
\text { pendent, } \mathrm{p}=0.017\end{array}$} \\
\hline
\end{tabular}

Although much current research places the blame for decreased outdoor activity squarely on administrators, the current findings suggest the source of these decisions may, in fact, be unclear. Is the decision to decrease or eliminate recess decided by the superintendent at the district level? Is there support or resistance by principals at the building level? Is the mandate of the curriculum coordinator at a program level affecting outdoor activities? Finally, is it lack of teacher knowledge and skill implementation that diminishes children's outdoor experiences?

As noted in the factor analysis in the Results section, Factor 1 showed high factor loadings on questions related to playground usage. This suggests that school playgrounds extend beyond the traditional steel-equipped, single-purpose areas. District administrators report that their school playgrounds have varied equipment in adequate condition. This broader notion of outdoor environment is further extended with data reporting that school playscapes include varied textures and places for children's reflection.

This finding is important because it suggests that district officials are aware that the outdoor arena serves a variety of purposes, including structured and unstructured play as well as vigorous and more reflective and aesthetic activities. The assumption may be made that district attempts to diversify the playscape and be inclusive suggest an implied under- standing of the importance of outdoor learning and play.

Typically, playgrounds are traditional in nature and restrict children's play to steel equipment with hard surface areas. Children are thus restrained in their play because the equipment is limited to one function (Frost, Wortham, \& Reifel, 2005). Hard surfaces facilitate the use of wheeled toys, but on the other hand, blacktop and concrete undermine children's running, rolling, and game play. Multiple textures provide for a range of play experiences.

The second factor, Diversity of Activity, shows high factor loadings suggesting that different textures afford a range of places for a wide range of activities involving atypical as well as typical children. Data suggest that district administrators are aware of the need for children's outdoor play and, make an effort to include children with special needs as a part of the outdoor schedule.

In addition to various textures and places for children's reflection, district officials indicated their understanding of the need to include different types of equipment. Equipment not only determines, but may also limit children's opportunities for play.

Data indicated that abundant portable equipment (balls, jump ropes,) contrasts with district administrators reporting a lack of movable equipment (bikes and scooters). This finding is not surprising. Although portable equipment costs less to purchase than traditional playground items like slides, balance beams, and climbers), storage proves difficult. Identifying a safe and easily accessible storage area for movable equipment is problematic. It is not convenient for teachers to store this equipment indoors and be responsible to carry it daily outdoors for children's play and or instruction. Easily accessible because of storage units, portable chairs and tables carried to the outdoor classroom create innovative opportunities for curriculum integration (McGinnis, 2002). Budgeting different types of equipment and accessible storage units becomes more viable when a commitment to outdoor learning and play is explicitly designated in a school district's policy.

The conclusions relating to running and ball play are unclear. School districts with running tracks and ball fields benefit older children who can play formal games with rules. Formalized tracks and ball fields 
do not ensure young and elementary children's informal running and ball play activities.

Finally, the loadings on Factor Three, Multiple Usage, indicate a strong relationship between varied textures and portable play equipment such as balls and jump ropes, as well as places for more reflective activities. As stated earlier, these findings are interpreted as suggesting district administrators' greater understanding of the importance of outdoor play than is indicated by the lack of written district policy.

Although the specificity of the playgrounds discussed by district officials is uncertain, their descriptions of varied textures and places for children's reflection are noteworthy because questions related to texture were highly loaded on all three factors. This indicates an awareness of the need for a variety of textures on playgrounds. An ideal playscape includes grass, sand, mulch, and blacktop.

In the past, children would go home after school to play with friends in the neighborhood. The increased numbers of working parents and singleparent households heightened the demand for afterschool supervision outside the home. Now, afterschool care is the responsibility of church, school, and professional care facilities.

In many instances, outdoor play in these afterschool locations is not a priority because of equipment, time, or supervision concerns. It is true that many children have access to after-school structured activities (i.e., dance, karate, soccer) but this is does not include all children, and the activities do not replace outside unstructured play. The excuse that children have other opportunities than school time for outdoor play and learning is no longer valid.

Different from inside play and learning, the time children spend with peers outside provides singularly unique opportunities for learning and development. In addition to the physical activity, children engage peers in experiences quite apart from traditional indoor learning.

Written district policy explicitly describing the role of outdoor learning and outdoor play ensures district-wide opportunities. A written district policy sends the message to building principals, teachers, and parents that the potential for children's learning and development in the outdoors is not negotiable.

If diminishing outdoor play and recess is an intentional district strategy, then efforts to assist admin- istrators' understanding of the potential of the outdoors is needed. However, although these data indicate that more students are spending less time outdoors, 62 percent remained the same. Decreasing or staying the same does nothing to improve the rising epidemic in childhood obesity. More time being active, not less, is needed. In addition to the research negating the three primary reasons for administrators decreasing time spent outside, the recent emphasis on improving childhood health provides a new opportunity to revise children's outdoor school play policy and practice.

The fact that children's outdoor learning and play has decreased should not be interpreted as the fault of administration. Administrators at all levels ask for accountability. Typically, district administrators are not grounded in developmentally appropriate practice, which includes the benefits of play and outdoor activity. On the other hand, are teachers capable of justifying the importance of outdoor learning and play? An informed faculty combined with supportive administrators could reverse this national trend. This support begins in preservice teacher education programs. Early childhood majors receive foundational learning about the importance of play because of the emphasis on developmentally appropriate practice. Typically elementary and middle school teacher candidates' understanding of outdoor play remains contingent on instructor's philosophy and choice of texts.

Too often, the task of playground design is relegated to interested-but not necessarily knowledgeable-parents, community members, and teachers. Frequently, the planning for the playscape is not directly related to the possibilities for the outdoor classroom. Administrators are responsible for leadership. The current data suggest that administrators are not necessarily intentionally mandating children away from outdoor activity. Instead, perhaps the data provide hope for district administrators' guidance toward quality outdoor experiences.

The research clearly demonstrates that play contributes to children's social, emotional, cognitive, and physical development. It is important for this knowledge to be passed on to the district level as policy. If not, uninformed preconceptions regarding outdoor play will continue. 


\section{Future Research}

The authors acknowledge the limitations of making inference from this sample to all U.S. school districts (i.e., limits to generalizability), but believe the effort to approximate an ideal random selection allows these data to initiate a discussion of the phenomenon of interest.

In order to extend understanding regarding quality outdoor play and learning opportunities, continued research at the district and policy level is suggested. Once district administrators identify outdoor activity and play as integral to children's learning and development, such expectations will frame practice for principals, classroom teachers, and parents. An examination of administrators' knowledge base related to outdoor learning and play would serve as initial data. These data could be compared with findings identifying playground designs and extended outdoor play arenas.

Although adequate time for outdoor play is important, the quality of outdoor activity itself is critical. An examination of what do school leaders know of this difference is noteworthy.

Data describing the differences between quality playscapes and traditional outdoor areas would provide information for policy-making discussions. Classroom teachers are also responsible for creating quality outdoor play and learning experiences. Examining what teachers know about the benefits of outdoor play and the implications for their outdoor instruction is needed to frame future professional development. Finally, parents cannot be left out of the discussion. Parents' perceptions of what counts as "real learning" shapes district policy. Study investigating parental attitudes toward outdoor play and learning allows more effective planning toward policy design and implementation.

\section{References}

Alexander, K.K. (1999). Playtime is cancelled. Parents Magazine (November): 114-118.

American Dietetic Association. (2003). Judging a healthy weight: Is there truth in numbers? Retrieved November 10, 2003, from www.eatright.org/Print/index_17169.cfm.

Archer, G. (1989). Big kids: Helping the overweight child. Pediatrics for Parents, 10(12), 2-3.
Burriss, K.G. \& Foulks Boyd B. (Eds.). (2005). Outdoor learning and play: Ages 8-12. Olney, MD: Association for Childhood Education International.

Burriss, K.G., \& Harrison, J.B. (2004). ACEI speaks: Obesity and children [Brochure]. Olney, MD: Association for Childhood Education International.

Chmelynski, C. (1998). Is recess needed? The Education Digest, 64, 67-68.

Dale, D., Corbin, C.B., \& Dale, K.S. (2000). Restricting opportunities to be active during school time: Do children compensate by increasing physical activity levels after school? Research Quarterly for Exercise and Sport, 71, 240-248.

Frost, J.L., Wortham, S.C., \& Reifel, S. (2005). Play and child development (2 ${ }^{\text {nd }}$ ed.).Columbus, $\mathrm{OH}$ : Merrill Prentice Hall.

Hall, K.R. (2006). Using problem-based learning with victims of bullying behavior. Professional School Counseling, 9, 231-237.

Healy, J. M. (1998). Failure to Connect: How Computers Affect Our Children's Minds- For Better and Worse. New York: Simon and Schuster.

Hofferth, S.L. \& Sandberg, J.F. (2000). Changes in American children's time, 1981-1997. Center for the Ethnography of Everyday Life. Retrieved May 17, 2006 from http://ceel.psc.isr.umich.edu/pubs/.

Jambor, T. \& Guddemi, M. (1992). Can our children play? In M. Guddemi \& T. Jambor (Eds.), A right to play: Proceedings of the American Affiliate of the International Association for the Child's Right to Play, (pp. 3-5). Little Rock, AR: Southern Early Childhood Association.

Jarrett, O.S., Maxwell, D.M., Dickerson, C., Hoge, P., Davies, G., \& Yetley, A. (1998). Impact of recess on classroom behavior: Group effects and individual differences. The Journal of Educational Research, 92, 12-126.

Katz, L.G. \& McClellan, D.E. (1997). Fostering children's social competence: The teacher's role. Washington, D.C.: National Association for the Education of Young Children.

Kenney, J.L., Militana, H.P., \& Donohue, M.H. (2003). Helping teachers to use their school's backyard as an outdoor classroom: A report on the watershed learning center program. The Journal of Environmental Education, 35, 18-26.

Kieff, J. (2001). The silencing of recess bells. Childhood Education, 77, 319-320. 
Kostelnik, M. J., Soderman, A. K., Stein, L. C., \& Whiren, A. P. (1993). Guiding

Children's Social Development. New York: Delmar Publishers Inc.

Leff, S.S., Power, T.J., Costigan, T.E., \& Manz, P.H. (2003). Assessing the climate of the playground and lunchroom: Implications for bullying prevention programming. School Psychology Review, 32, 418-430.

Lieberman, G.A. \& Hoody, L. (1998). Closing the achievement gap: Using the environment as an integrating context for learning. San Diego: State Education and Environment Roundtable.

McGinnis, J. R. (2002, May). Enriching the outdoor environment. Young Children, 57, 28-30.

National Association of Early Childhood Specialists (NAECS) in State Departments of Education. (2001). Recess and the importance of play. A position statement on young children and recess. Washington, D.C.: Office of Educational Research and Improvement.

National Institute of Child Health and Human Development of Study of Early Child Careand Youth Development Network. (2003). Frequency and intensity of activity ofthird-grade children in physical education. Archives of Pediatrics \& AdolescentMedicine, 157, 185-191.

Pellegrini, A.D. \& Bjorkland, D.F. (1996). The place of recess in school: Issues in the role of recess in children's education and development. An introduction to the theme issue. Journal of Research in Childhood Education, 11, 5-13.

Pellegrini, A.D. \& Bohn, C.M. (2005). The role of recess in children's cognitive performance and school adjustment. Educational Researcher, 34, 1319.

Pellegrini, A.D., Huberty, P.D., \& Jones, I. (1995). The effects of recess timing on children's classroom and playground behavior. American Educational Research Journal, 32, 845-864.

Pellegrini, A.D. \& Smith, P. K. (1993). School recess: Implications for education and development. Review of Educational Research, 63, 51-67.

Pellegrini, A.L. (1995). School recess and playground behavior: Educational \& developmental roles. Albany: State University of New York Press.
Piaget, J. (1983). In W. Kessen (Ed.), Handbook of child psychology: History, theory, and methods (pp. 103-128). New York: Wiley.

Rubin, K.H. (1980). Fantasy play: Its role in the development of social skills and social cognition. In K.H. Rubin (Ed.), Children's play (pp. 69-84). San Francisco: Jossey-Bass.

Sommerset, B. (2000). Outdoor schooling. The Delta Kappa Gamma Bulletin, 66, 45-49.

Sothern, M., \& Gordon, S. (2003). Prevention of obesity in young children: A critical challenge for medical professionals. Clinical Pediatrics, 42, 101111.

Stone, S.J. (2005). Becoming an advocate for play in the elementary and middle school years. In K.G. Burriss \& B. Foulks-Boyd (Eds.), Outdoor learning and play, ages 8-12. Olney, MD: Association for Childhood Education International.

Sullivan, M. (2003). Web site helps overweight children. Pediatric News, 37(2), 32.

Wagner, C. (2000). Planning school grounds for outdoor learning. National Clearinghouse for Educational Facilities, 1-7. 